\title{
TRAIL and TRAIL Receptors as Prognostic Markers in Breast Cancer Patients
}

\author{
Fawziya A. R. Ibrahim ${ }^{*}{ }^{(}$, Marwa S. Abouelenein ${ }^{2}$, Ola S. A. Sakr ${ }^{3}$, Sanaa S. Ahmed4, \\ Ebtisam R. Zaher ${ }^{2}$, Shaymaa E. el Feky²
}

\begin{abstract}
${ }^{1}$ Department of Applied Medical Chemistry, Medical Research Institute, University of Alexandria, Alexandria, Egypt
${ }^{2}$ Department of Radiation Sciences, Medical Research Institute, University of Alexandria, Alexandria, Egypt

${ }^{3}$ Department of Cancer Management and Research Medical Research Institute, University of Alexandria, Alexandria, Egypt

${ }^{4}$ Pathology Department, Medical Research Institute, University of Alexandria, Alexandria, Egypt

Email: *d.fawziyaibrahim@gmail.com
\end{abstract}

How to cite this paper: Ibrahim, F.A.R., Abouelenein, M.S., Sakr, O.S.A., Ahmed, S.S., Zaher, E.R. and el Feky, S.E. (2019) TRAIL and TRAIL Receptors as Prognostic Markers in Breast Cancer Patients. American Journal of Molecular Biology, 9, 204-217.

https://doi.org/10.4236/ajmb.2019.94015

Received: August 23, 2019

Accepted: September 20, 2019

Published: September 23, 2019

Copyright $\odot 2019$ by author(s) and Scientific Research Publishing Inc. This work is licensed under the Creative Commons Attribution International License (CC BY 4.0).

http://creativecommons.org/licenses/by/4.0/

\begin{abstract}
Background: Tumor necrosis factor-related apoptosis-inducing ligand (TRAIL) is a key player in the extrinsic pathway of apoptosis; it selectively damages cancer cells through binding to its surface receptors, however, cancers can escape this pathway through expression of dysfunctional decoy receptors. Purpose: The present study directed mainly to elucidate the serum TRAIL levels in breast cancer patients and to explore the variation in gene expression of TRAIL death and decoy receptors in breast cancer tissues, and to explore their role as prognostic markers in breast cancer as well as to detect their correlation with Patients' Clinical Characteristics. Subjects and Methods: TRAIL levels were assayed in the sera of 124 breast cancer patients and 150 healthy females. Moreover, the expression of TRAIL death and decoy receptors was determined in both malignant and adjacent normal breast tissues collected from patients. ER, PR and Her-2 expression in breast cancer tissue were performed using immunohistochemical method. Apoptotic index (AI) was analyzed using H\&E stain under light microscopy. Results: Serum levels of TRAIL in breast cancer patients were significantly lower than controls $(\mathrm{P}<$ 0.001 ), additionally, the expression of DR4, DR5 and DcR1 were significantly up-regulated ( $\mathrm{p}<0.001, \mathrm{p}<0.001, \mathrm{p}=0.039$, respectively), however, no significant difference was found in the expression of DcR2 in breast cancer tissues as compared to the corresponding normal tissues. Moreover, the apoptotic index in breast cancer tissues was significantly higher than the corresponding normal tissues. On the other side, decreased Serum TRAIL levels and increased DcR1 expression were associated with decreased overall patients' survival. Conclusions: The expression of both DR4 and DR5 is required for TRAILinduced apoptosis in breast cancer tissues; in addition, serum TRAIL and pro-
\end{abstract}


filing of TRAIL receptors expression may serve as prognostic markers in breast cancer patients.

\section{Keywords}

Breast Cancer, Apoptosis, TRAIL, Prognosis

\section{Introduction}

One of the most essential hallmarks of cancer is apoptosis-resistance [1]. Cancer cells escape apoptosis either through the overexpression of anti-apoptotic proteins or the inhibition of the pro-apoptotic signals. With regard to breast cancer (BC), previous studies reported resistance of BC cells to receptor-mediated apoptosis, even with the presence of receptors in cancer cells [2].

Tumor necrosis factor-related apoptosis-inducing ligand (TRAIL) is expressed mainly by immune system cells; it triggers the extrinsic pathway of apoptosis through interacting with its surface receptors expressed on the target cells. TRAIL binds to two pro-apoptotic receptors known as death receptor 4 (DR4/ TRAIL-R1), death receptor 5 (DR5/TRAIL-R2), and two decoy receptors DcR1 (TRAIL-R3), DcR2 (TRAIL-R4) [3]. As their names imply, only two of these receptors (TRAIL-R1 and TRAIL-R2) are functional death receptors as they possess the functional cytoplasmic domain and are capable of transmitting the apoptotic signals into cells. Conversely, TRAIL-R3 and TRAIL-R4 are decoy receptors that lack the functional death domains (DD), and their overexpression may result in blocking of TRAIL-mediated apoptosis [4].

Interestingly, TRAIL preferentially induce apoptosis and kill cancer cells without affecting normal cells, thus rendering it a highly promising approach in cancer treatment [5]. However, cancer cells express innate or acquired resistance to TRAIL-induced apoptosis through the expression of the dysfunctional decoy receptors (DCR1 and DcR2); these receptors compete with the functional death receptors (DR4 and DR5) for the binding sites on TRAIL. Binding to decoy receptors disrupts TRAIL-induced apoptosis through either ability to dilute out TRAIL ligands (like DcR1) or supply anti-apoptotic signals (like DcR2) to cells [6].

On the other side, TRAIL-induced apoptosis is crucial for tumor surveillance through induction of immune-mediated clearance of metastatic cells [7], loss of TRAIL receptor-expression is associated with worse prognosis and tumor recurrence in patients suffering from different tumors [8]. Additionally, increased expression of decoy receptors correlated with both tumor stage and metastasis in patients suffering from colorectal cancer [9]. In spite of the increasing interest for TRAIL-receptors as therapeutic approach in management of cancer, studies on the genetic expression, distribution and relevance of TRAIL-receptors as prognostic markers in breast cancer are still lacking.

To the best of our knowledge, few previous studies concern with the variation 
in serum TRAIL level and the expression of TRAIL receptors in breast cancer, and no correlation studies linked the expression of TRAIL receptors to prognosis among breast cancer patients. Therefore, the present study is directed mainly toward elucidating the variation of gene expression of TRAIL receptors R1-R4 in $\mathrm{BC}$ tissues, and to explore their role as prognostic markers in breast cancer.

\section{Subjects and Methods}

\subsection{Subject}

The present study included 274 females categorized in two groups; Group 1 included 124 females diagnosed with primary breast cancer and Group 2 included 150 age-matched normal healthy females as a control group. Patients were selected from those admitted to the Cancer Management and Research Depratment, Medical Research Institute, Alexandria University during the period from October 2012 till February 2014, all patients had histologically confirmed operable, non-metastatic breast cancer. Patients who had second primary malignancy or distant metastasis, previous radio or chemotherapy, myeloplastic syndrome, active Hepatitis B or C, psychitric diseases or any other diseses preventing signing the informed consent were excluded from the study. This study was approved by the local ethics committee, Medical Research Institute, Alexandria University.

\subsection{Sample Collection}

After providing an inforned consent a blood sample was withdrawn from all enrolled participants. Subjects' sera were kept at $-80^{\circ} \mathrm{C}$ until the time of use. All enrolled patients underwent modified radical mastectomy. During surgery, two tissue samples were taken, one from the resected tumor and the other from the adjacent apparently normal tissue. A part of each tissue was embedded in paraffin for histopathological examinations, while the rest was immediately transferred to $-80^{\circ} \mathrm{C}$ for further analysis. Patients were clinically followed up for a mean time of 60 months.

\subsection{Methods}

\subsubsection{Apoptotic Index (AI)}

From the paraffin embedded tissue, two $4 \mu \mathrm{m}$ thickness sections were stained with hematoxylin and eosin (H\&E) for calculating the apoptotic index (AI). The H\&E stained sections were examined using oil immersion lenses $(\times 100)$. From each section, 10 fields devoid of artifacts were selected. 1000 cells were evaluated for presence of apoptotic cells and apoptotic bodies. The AI was expressed as a percentage of the total number of non-apoptotic cells counted.

\subsubsection{Quantification of Genetic Expression of DR4, DR5, DcR1 and DcR2 by qPCR}

Singleplex fluorescent-based quantitative real-time PCR assay (qPCR) was performed for the determination of the genetic expression of DR4, DR5, DcR1 and DcR2 in the breast cancer and normal tissue specimens. Total RNA was ex- 
tracted from $100 \mathrm{mg}$ of the collected tissues (tumor as well as normal tissues) using miRNeasy mini kit (QIAGEN Co, Hilden, Germany), according to the manufacturer's instructions. The purity and concentration of extracted RNA were mesured by NanoDrop ${ }^{(\mathrm{R})}$ ND-1000 UV-Visible Spectrophotometer (Thermo Fischer Scientific, USA). The extracted total RNA was then reversely transcribed using Quantitect RT kit (QIAGEN Co, Hilden, Germany) following the manufacturer's instructions. The quantitative PCR analysis was performed using SYBR Green Master mix (Bio-Rad Laboratories, Inc., USA). The thermal profile consisted of $10 \mathrm{~min} / 95^{\circ} \mathrm{C}$ activation step, followed by 40 cycles of denaturation for $20 \mathrm{sec} / 95^{\circ} \mathrm{C}$ and the primer annealing and extension for $1 \mathrm{~min} / 60^{\circ} \mathrm{C}$ on a Real Time PCR Detection System (Bio-Rad Laboratories, Inc., USA). Relative quantification analysis for the DR4, DR5, DcR1 and DcR2 mRNA expression was calculated by the comparative $2^{-\triangle \mathrm{CT}}$ method. mRNA expression of all genes was normalized using the GAPDH reference gene, the primer pair used for each gene are represented in Table 1.

Table 1. Real-time PCR primers.

\begin{tabular}{clc}
\hline Treget gene & \multicolumn{1}{c}{ Primer sequence } & Annealing temperature \\
\hline$\underline{\text { DR4 }}$ & $\begin{array}{l}\text { Forward: 5'-TCCAGCAAATGGTGCTGAC-3' } \\
\text { Reverse: 5'-GAGTCAAAGGGCACGATGTT-3' }\end{array}$ & $60^{\circ} \mathrm{C}$ \\
$\underline{\text { DR5 }}$ & $\begin{array}{l}\text { Forward: 5'-CCAGCAAATGAAGGTGATCC-3' } \\
\text { Reverse: 5'-GCACCAAGTCTGCAAAGTCA-3' }\end{array}$ & $61^{\circ} \mathrm{C}$ \\
$\underline{\text { DcR1 }}$ & $\begin{array}{l}\text { Forward: 5'-TCCTGCTGCCAGTCCTAGCTTAC-3 } \\
\text { Reverse: 5'-TGAGATCCTGCTGGACACTCCTC-3' }\end{array}$ & $61^{\circ} \mathrm{C}$ \\
$\underline{\text { DcR2 }}$ & $\begin{array}{l}\text { Forward: 5'-GCCGGTCCGGGTTGACTC-3' } \\
\text { Reverse: 5'-TGAGATCCTGCTGGACACTCCT-3' }\end{array}$ & $60^{\circ} \mathrm{C}$ \\
$\underline{\text { GADPH }}$ & $\begin{array}{l}\text { Forward: 5'-TGCACCACCAACTGCTTAG-3' } \\
\text { Reverse: 5'-GGATGCAGGGATGATGTT-3' }\end{array}$ & $58^{\circ} \mathrm{C}$ \\
\hline
\end{tabular}

\subsubsection{Serum TRAIL Quantification Assay}

Quantitative determination of serum levels of TRAIL in the sera of enrolled patients as well as control subjects was done using an Enzyme-linked Immunosorbent Assay (ELISA) Kit (Uscn Life Science Inc., China) according to the manufacturer's instructions.

\subsubsection{Immunohistochemical Staining for ER, PR, Her-2Neu Receptors}

Thin $5 \mu \mathrm{m}$ sections were cut from each paraffin-embedded specimen, transferred onto poly-L-lysine-coated slides, deparaffinized in xylene, rehydrated in descending ethanol series followed by distilled water, rinsed in phosphate-buffered saline (PBS), then immersed in pre-heated $0.01 \mathrm{M}$ citrate buffer at $\mathrm{pH} 6.0$ at $\left(95^{\circ} \mathrm{C}\right.$ $99^{\circ} \mathrm{C}$ ) for 40 minute. After cooling down, tissue sections were incubated with the primary ER, PR and Her-2neu primary rabbit monoclonal antibodies in a humidity chamber overnight at room temperature then incubated with biotinylated rabbit anti-mouse secondary antibody for 30 minutes. Streptavidin-conjucated horseradish peroxidase was added for 30 mins. The bound primary antibodies were 
visualized by avidin-biotin complex assay (DAKO) with 3,30-diaminobenzidine tetrahydrochloride $(\mathrm{DAB})$ and the sections were counterstained with Meyer's Haematoxylin, washed with water, dehydrated through alcohol, cleared in xylene, and mounted on coverslips with DPX. The nuclear positivity for ER and PR was determined as per the Allred score. Her2new scoring was also done according to standard criteria [10] [11].

\subsubsection{Statistical Analyses}

Data were analyzed using SPSS software package version 20.0 (IBM Corporation, Chicago, Illinois, USA). The distributions of quantitative variables were tested for normality using Kolmogorov-Smirnov test. Mann-Whitney test was used to compare between two studied groups, for Kruskal Wallis test was used to compare between more than two groups. Wilcoxon signed ranks test was used to compare expression levels between cancer and adjacent normal tissues, Spearman correlation test was used to study the correlation with the clinicopathological parameters. Cox proportional hazards regression model analysis was done to investigate the prognostic value of studied parameters. At all statistical analyses, $\mathrm{p}$ value was considered significant at $\leq 0.05$.

\section{Results}

\subsection{Patients' Clinical Characteristics}

The clinicopathological characteristics of the enrolled patients are presented in Table 2. The median age of enrolled patients didn't differ significantly from that

Table 2. Description of the clinicopathological features of breast cancer patients and controls.

\begin{tabular}{|c|c|c|c|}
\hline \multicolumn{2}{|c|}{ Characteristic } & \multirow{3}{*}{$\begin{array}{c}\text { Breast cancer (124) } \\
\text { Number (\%) } \\
48 \\
37-74\end{array}$} & \multirow{2}{*}{$\begin{array}{c}\text { Controls (150) } \\
46\end{array}$} \\
\hline A sre (years) & Median & & \\
\hline Age (years) & range & & $36-74$ \\
\hline Tumor size $\mathrm{cm}$ & $($ Mean \pm SD $)$ & $4.6 \pm 3.4$ & \\
\hline \multirow{3}{*}{ Histological grade } & I & $11(8.9)$ & \\
\hline & II & $62(50.0)$ & \\
\hline & III & $51(41.1)$ & \\
\hline \multirow{3}{*}{ Clinical stage } & I & $11(8.9)$ & \\
\hline & II & $53(42.7)$ & \\
\hline & III & $60(48.4)$ & \\
\hline \multirow{2}{*}{ Estrogen receptor } & negative & $36(29.0)$ & \\
\hline & positive & $88(71.0)$ & \\
\hline \multirow{2}{*}{ Progesterone receptor } & negative & $42(33.9)$ & \\
\hline & positive & $82(66.1)$ & \\
\hline \multirow{2}{*}{ Lymph node invasion } & negative & $54(43.5)$ & \\
\hline & positive & $70(56.5)$ & \\
\hline \multirow{2}{*}{ Vascular invasion } & negative & $53(42.7)$ & \\
\hline & positive & $71(57.3)$ & \\
\hline
\end{tabular}


of control. Regarding the clinical stage, about half of patients were of stage III. Moreover, $50 \%$ of specimens were of histological grade II. Majority of cases represented with positive ER and PR expression. Vascular invasion and lymph node involvement was positive in $43.5 \%$ and $42.7 \%$ of cases, respectively.

\subsection{Decreased Serum Levels of TRAIL in Sera of Breast Cancer Patients Compared to Healthy Subjects}

The serum TRAIL levels in breast cancer patients were found to be significantly lower than those in the healthy control $(\mathrm{P}<0.001)$ (Figure $1(\mathrm{a})$ ).

\subsection{Genetic Expression of TRAIL Death/Decoy Receptors and Apoptotic Index in Breast Cancer Tissues}

The apoptotic index in breast cancer tissues was significantly higher than that in the corresponding normal tissues $(\mathrm{P}<0.001)$ (Figure $1(\mathrm{~b})$ ). Moreover, the expression of DR4, DR5 and DcR1 showed a significant up-regulation in cancerous tissues as compared to normal tissues $(\mathrm{p}<0.001, \mathrm{p}<0.001, \mathrm{p}=0.039$, respectively), however, the genetic expression of DcR2 didn't show any significant difference between cancerous tissues and normal tissues $(\mathrm{p}>0.05)$ (Figure 1(c)).

\subsection{TRAIL, DR4, DR5, DcR1 and DcR2 Are Correlated to Apoptotic Index}

Apoptotic index showed significant positive correlations with both serum TRAIL levels and expression of DR4; however, it had a significant negative correlation with expression of DcR1. On the other hand, the expression of DR5 and DcR2 didn't show any significant correlation with apoptotic index (Table 3).

\subsection{TRAIL, DR4, DR5, DcR1 and DcR2 Are Correlated to Clinicopathological Characteristics}

Serum TRAIL levels showed a significant negative correlation with tumor size, grade, and clinical stage, but the correlation with receptor status, lymph node invasion, and vascular invasion was found to be insignificant. On the other hand, the expression of DcR1 showed a significant positive correlation with tumor size, however, TRAIL DR4, DR5 and DcR2 didn't show any significant correlation with any of the clinicopathological parameters (Table 3). On the other side, Apoptotic index correlated negatively with the grade, while positively correlated with the positive expression of ER and PR (Table 3).

\subsection{Association between TRAIL, DR4, DR5, DcR1, DcR2 and Apoptotic Index and Clinicopathological Characteristics}

Stratification analyses revealed significant association between serum TRAIL levels with lower histological grade and clinical stage, and between the expression of DcR1 with the tumor stage. Moreover, both serum TRAIL and DcR1 expression showed a significant association with mortality among BC patients (Table 4). 

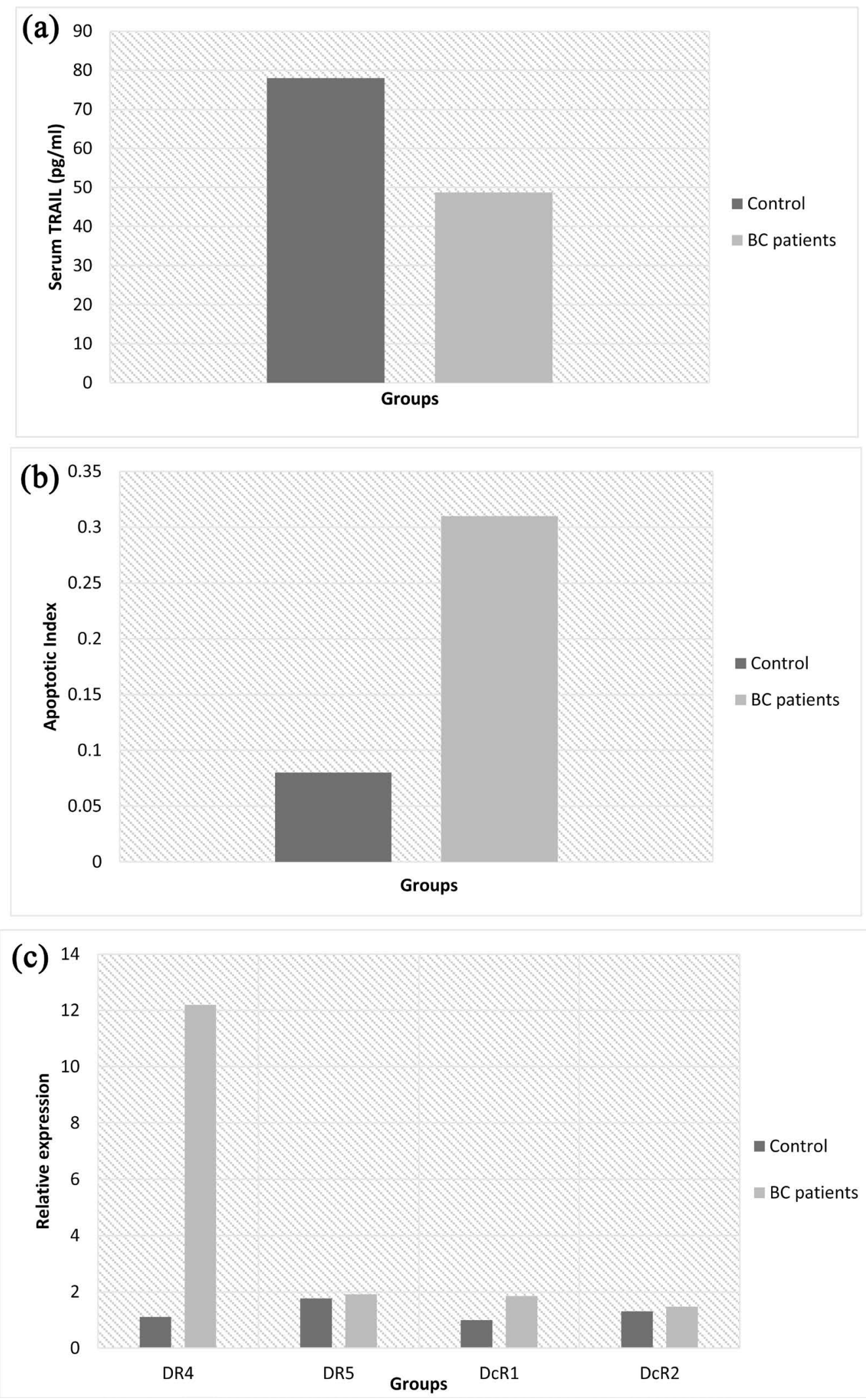

Figure 1. (a) serum TRAIL levels in BC patients and healthy controls, (b) apoptotic index in malignant tissues and adjacent normal tissues, (c) relative expression of DR4, DR5, DcR1, and DcR2 in malignant tissues and adjacent normal tissues. 
Table 3. Correlation between different parameters in BC-patients $(n=124)$.

\begin{tabular}{|c|c|c|c|c|c|c|c|}
\hline & & AI & TRAIL & RD4 & DR5 & DcR1 & DcR2 \\
\hline \multirow[t]{2}{*}{ Tumor size } & $\mathbf{r}_{\mathrm{s}}$ & 0.161 & -0.670 & -0.093 & 0.127 & 0.203 & -0.122 \\
\hline & $\mathrm{p}$ & 0.072 & $<0.001^{\star}$ & 0.302 & 0.161 & $0.024^{*}$ & 0.177 \\
\hline \multirow[t]{2}{*}{ Histological grade } & $\mathbf{r}_{\mathrm{s}}$ & -0.201 & -0.224 & -0.019 & 0.048 & 0.093 & 0.158 \\
\hline & $\mathrm{p}$ & $0.025^{*}$ & $0.013^{*}$ & 0.834 & 0.597 & 0.302 & 0.080 \\
\hline \multirow[t]{2}{*}{ Clinical stage } & $\mathbf{r}_{\mathrm{s}}$ & 0.107 & -0.248 & 0.114 & 0.022 & 0.006 & 0.127 \\
\hline & $\mathrm{p}$ & 0.228 & $0.006^{*}$ & 0.207 & 0.808 & 0.950 & 0.159 \\
\hline \multirow[t]{2}{*}{$\mathrm{ER}^{+} / \mathrm{PR}^{+}$} & $\mathbf{r}_{s}$ & 0.166 & 0.110 & 0.144 & -0.173 & 0.028 & 0.041 \\
\hline & $\mathrm{p}$ & $0.042^{\star}$ & 0.213 & 0.103 & 0.392 & 0.754 & 0.568 \\
\hline \multirow[t]{2}{*}{ Lymph nodes invasion } & $\mathbf{r}_{\mathrm{s}}$ & 0.048 & 0.072 & 0.151 & 0.039 & 0.117 & 0.140 \\
\hline & $\mathrm{p}$ & 0.551 & 0.327 & 0.111 & 0.663 & 0.189 & 0.131 \\
\hline \multirow[t]{2}{*}{ Vascular invasion } & $\mathbf{r}_{s}$ & 0.141 & 0.126 & -0.047 & 0.113 & 0.105 & 0.072 \\
\hline & $\mathrm{p}$ & 0.129 & 0.177 & 0.594 & 0.208 & 0.247 & 0.327 \\
\hline \multirow[t]{2}{*}{ Apoptotic index } & $\mathbf{r}_{s}$ & & 0.412 & 0.385 & 0.149 & -0.187 & 0.042 \\
\hline & $\mathrm{p}$ & & $<0.001^{\star}$ & $<0.001^{*}$ & 0.098 & $0.037^{*}$ & 0.572 \\
\hline
\end{tabular}

rs: Spearman coefficient; ${ }^{*}$ : Statistically significant at $\mathrm{p} \leq 0.05$.

Table 4. Stratification analyses of TRAIL, DR4, DR5, DcR1, and DcR2 in patients with different clinicopathological status.

\begin{tabular}{cccccc}
\hline & TRAIL & DR4 & DR5 & DcR1 & \multicolumn{1}{c}{ DcR2 } \\
\hline ER & & & & & \\
- & $50.1 \pm 21$ & $12.8 \pm 5.9$ & $1.9 \pm 0.4$ & $1.9 \pm 0.4$ & $1.4 \pm 0.2$ \\
+ & $48.1 \pm 26.9$ & $11.9 \pm 5.8$ & $1.9 \pm 0.4$ & $1.8 \pm 0.5$ & $1.5 \pm 0.2$ \\
U (p) & $1409(0.336)$ & $1949.5(0.459)$ & $1576.5(0.967)$ & $1308.5(0.129)$ & $1235.0(0.054)$ \\
PR & & & & & \\
- & $52.2 \pm 23.5$ & $12.8 \pm 5.8$ & $1.9 \pm 0.4$ & $1.9 \pm 0.4$ & $1.4 \pm 0.2$ \\
+ & $47 \pm 26.1$ & $11.9 \pm 5.9$ & $1.9 \pm 0.4$ & $1.8 \pm 0.5$ & $1.5 \pm 0.2$ \\
U (p) & $1422(0.113)$ & $1556(0.318)$ & $1676.0(0.808)$ & $1500(0.241)$ & $1442.5(0.140)$
\end{tabular}

Lymph node involvement

$\begin{array}{cccccc}- & 50.8 \pm 25.9 & 12.4 \pm 5.5 & 1.9 \pm 0.4 & 1.8 \pm 0.4 & 1.4 \pm 0.2 \\ + & 47.1 \pm 24.8 & 12 \pm 6.1 & 1.9 \pm 0.4 & 1.9 \pm 0.5 & 1.5 \pm 0.2 \\ \mathrm{U}(\mathrm{p}) & 1716(0.380) & 1825.5(0.745) & 1682.5(0.295) & 1813.5(0.700) & 1684.0(0.299)\end{array}$

Histological grade

\begin{tabular}{cccccc} 
I & $63 \pm 41.2$ & $10.4 \pm 5.6$ & $2 \pm 0.6$ & $1.7 \pm 0.4$ & $1.4 \pm 0.3$ \\
II & $51.1 \pm 22$ & $13 \pm 5.6$ & $1.9 \pm 0.3$ & $1.8 \pm 0.5$ & $1.4 \pm 0.2$ \\
III & $42.7 \pm 23.4$ & $11.6 \pm 6.1$ & $1.9 \pm 0.5$ & $1.9 \pm 0.5$ & $1.5 \pm 0.2$ \\
H (p) & $6.299\left(0.044^{*}\right)$ & $3.009(0.209)$ & $0.874(0.646)$ & $0.957(0.620)$ & $2.218(0.330)$ \\
Clinical stage & & & & & \\
II & $67.2 \pm 34.9$ & $12.4 \pm 4.7$ & $2 \pm 0.6$ & $1.8 \pm 0.4$ & $1.5 \pm 0.2$ \\
III & $51 \pm 23.4$ & $11.1 \pm 5.6$ & $1.9 \pm 0.3$ & $1.9 \pm 0.4$ & $1.4 \pm 0.2$ \\
\hline
\end{tabular}




\section{Continued}

\begin{tabular}{cccccc}
\hline IV & $43.3 \pm 23.3$ & $13.1 \pm 6.1$ & $1.9 \pm 0.4$ & $1.8 \pm 0.5$ & $1.5 \pm 0.2$ \\
H (p) & $8.225\left(0.016^{\star}\right)$ & $3.133^{*}\left(0.042^{\star}\right)$ & $0.461(0.794)$ & $0.664(0.718)$ & $7.064^{\star}\left(0.029^{*}\right)$ \\
\multicolumn{2}{l}{ Vascular invasion } & & & & \\
- & $52.9 \pm 27.9$ & $12.2 \pm 5.4$ & $1.9 \pm 0.4$ & $1.8 \pm 0.5$ & $1.5 \pm 0.2$ \\
+ & $45.6 \pm 22.8$ & $12.2 \pm 6.2$ & $1.9 \pm 0.4$ & $1.9 \pm 0.5$ & $1.5 \pm 0.2$ \\
U (p) & $1578\left(0.125^{*}\right)$ & $1877(0.982)$ & $1792.5(0.653)$ & $1800.5(0.682)$ & $1842.5(0.844)$ \\
Mortality & & & & & \\
Alive & $28.6 \pm 13.9$ & $12.9 \pm 6.2$ & $1.9 \pm 0.4$ & $2.2 \pm 0.4$ & $1.5 \pm 0.2$ \\
Died & $58 \pm 23.9$ & $11.9 \pm 5.7$ & $1.9 \pm 0.4$ & $1.7 \pm 0.4$ & $1.5 \pm 0.2$ \\
U (p) & $360.5\left(0.001^{*}\right)$ & $1475(0.326)$ & $1512.0(0.433)$ & $604\left(0.001^{*}\right)$ & $1541.0(0.530)$ \\
\hline
\end{tabular}

U: Mann Whitney test; $\mathrm{H}: \mathrm{H}$ for Kruskal Wallis test; $\mathrm{p}$ : $\mathrm{p}$ value for association between studied parameters and different parameters; ${ }^{*}$ : Statistically significant at $\mathrm{p} \leq 0.05$.

\subsection{Decreased Serum TRAIL and Overexpression of DcR1 Are Prognostic Factors for Poor Overall Survival among BC Patients}

Univariate and multivariate analyses were performed on BC cases to identify factors that correlate with prognosis using Cox proportional hazards regression model analysis. The results showed that decreased serum TRAIL ( $\mathrm{p} \leq 0.001)$, increased expression of DcR1 ( $\mathrm{p} \leq 0.001$ ), were associated with worse overall survival. Moreover, the multivariate analysis indicated that they can be independent prognostic factors for overall survival among BC patients (Table 5).

Table 5. Univariate and multivariate Cox regression for prediction mortality.

\begin{tabular}{ccccc}
\hline & \multicolumn{2}{c}{ Univariate } & \multicolumn{2}{c}{ Multivariate } \\
\cline { 2 - 5 } & HR $(95 \%$ C.I. $)$ & p & HR $(95 \%$ C.I. $)$ & p \\
\hline TRAIL & $0.937(0.918-0.957)$ & $<0.001^{*}$ & $0.919(0.890-0.949)$ & $<0.001^{*}$ \\
Tumor size & $1.314(1.176-1.468)$ & $<0.001^{*}$ & $0.903(0.759-1.075)$ & 0.251 \\
Histological grade & $1.940(1.121-3.356)$ & $0.018^{*}$ & $1.042(0.537-2.020)$ & 0.904 \\
Clinical stage & $2.279(1.269-4.091)$ & $0.006^{*}$ & $1.540(0.734-3.233)$ & 0.254 \\
ER & $0.770(0.458-1.783)$ & 0.903 & & \\
PR & $1.009(0.518-1.964)$ & 0.979 & & \\
Lymph node & $1.536(0.798-2.955)$ & 0.199 & & \\
Vascular invasion & $1.472(0.765-2.832)$ & 0.247 & & \\
DR4 & $1.031(0.975-1.090)$ & 0.288 & & \\
DR5 & $0.778(0.349-1.737)$ & 0.541 & & \\
DcR1 & $8.543(4.422-16.504)$ & $<0.001^{*}$ & $6.569(3.419-12.619)$ & \\
DcR2 & $0.670(0.163-2.743)$ & 0.577 & & \\
\hline
\end{tabular}

HR: Hazard ratio; C.I.: Confidence interval; \#: All variables with $\mathrm{p}<0.05$ were included in the multivariate; *: Statistically significant at $\mathrm{p} \leq 0.05$. 


\section{Discussion}

TRAIL is a key member of TNF family that induces apoptosis upon binding to its surface receptors; because of the unique selectivity of TRAIL in damaging cancer cells without any harmful effects to the normal cells, TRAIL became a promising therapeutic approach in cancer management; moreover, it has been already entered in some clinical trials for treatment of many solid tumors. However, some tumors unfortunately develop resistance to TRAIL-mediated apoptosis through expression of decoy receptors instead of death receptors [12]. Therefore, the expression of TRAIL death receptors and the downstream signaling molecules of the TRAIL pathway represent prerequisite for TRAIL-based therapies. Furthermore, the expression ratio of death and decoy receptors may be decisive for the sensitivity of tumor cells to TRAIL [13]. Therefore, we investigated the serum levels of TRAIL in BC patients in addition to analysis of the expression pattern of death as well as decoy receptors in BC tissues.

The present study revealed a significant decrease in serum TRAIL level in breast cancer patients; these findings are in accordance with those of Toiyama $\mathrm{D}$ who demonstrated that serum TRAIL levels in RCC patients were markedly lower than the healthy controls [14]. Additionally, few previous studies reported a decrease in serum TRAIL levels in many cancers including metastatic melanoma [15] and chronic myeloid leukemia [16] as compared to its levels in healthy individuals.

Decreased TRAIL increase the ability of cancerous cells to evade immune surveillance and apoptosis, this in turn prompts cancer development and progression [14]. In RCC, serum TRAIL levels increased significantly after the complete resection of the primary tumor. This may be attributed to the involvement of cancer cells in the inhibition of TRAIL production circulation via two possible effects. First, cells may secrete some soluble factors that can inhibit immune cells production of TRAIL, such as lymphocytes. The second possible mechanism may be through sequestration of TRAIL-producing immune, resulting in decreased serum TRAIL levels [14]. This hypothesis can be supported by the finding of Liu et al. who reported decreased expression of TRAIL in breast cancer tissues comparing to the adjacent normal tissues [17]. Moreover, removal of the renal tumor might result in the return of circulating TRAIL levels to baseline values [14].

The significant upregulation of TRAIL DR4 and DR5 may be attributed to the fact that the increased expression of TRAIL receptors may enhance the apoptotic response induced by TRAIL and lead to an increase in the apoptotic rate among tumor cells [18] [19]. These results were supported by the positive correlation between the expressions of TRAIL DR4 and the apoptotic index in the breast cancer tissues. Previous studies indicated possible selectivity of DR4 vs. DR5 apoptotic signaling in tumor cells from different origins. Tumors such as pancreatic carcinoma [20], chronic lymphocytic leukemia or mantle cell lymphoma prefer DR4 for apoptosis induction [21] [22]; other types, including colorectal or other epithelial cancer cells appear to prefer DR5 as an apoptosis inducer [23] [24]. Regarding BC, Zhang et al. reported that the expression of both DR4 and 
DR5 are required for rhTRAIL to induce the maximal killing effect of breast cancer cells, moreover, the loss of cell surface expression of DR4 or DR5 lead to cellular resistance to their corresponding antibody and correlates with a decreased sensitivity of cells to TRAIL [25].

On the other hand, the significant overexpression of DcR1 overexpression in malignant tissues contributes to ability of cancerous cells to evade the TRAILmediated apoptosis. TRAIL-R3 and TRAIL-R4 decoy receptors lack the functional intercellular death domain, this in turn prevent their association with procaspases 8 and 10 to form DISC which is mandatory for activating downstream signaling pathway [26]. A previous study documented a significant upregulation of decoy-R1 (DcR1) but a downregulation in decoy-R2 (DcR2) in head and neck cancers [27]. Moreover, the expression of DcR2 was reported to be significantly increased in high grade meningiomas [28], DcR2 binds to TRAIL-R2 via the pre-ligand-binding assembly domain (PLAD) [29], thus the overexpression of DcR2 neutralizes the apoptosis-inducing capacity of TRAIL-DR5 and confers TRAIL resistance in higher tumor grades. Accordingly, DcR2 overexpression has been reported to inhibit TRAIL-induced apoptosis in many tumors [30] [31].

The negative correlation between serum TRAIL level and with tumour size, grade, and clinical stage, are in accordance with Toiyama D who reported inverse correlation between the serum TRAIL level the progression and aggressiveness of RCC. These findings suggest that decreased TRAIL may allow cancer cells to escape immune surveillance and apoptosis [14]. Verim A also indicated a statistically significant association between TRAIL, and clinical parameters including stage, lymph node, metastasis, perineural invasion and degree of tumor differentiation in Lx SCC patients [32].

Decreased serum TRAIL levels and overexpression of DcR1 were associated with decreased overall survival among breast cancer patients, these findings are in accordance partly with Toiyama $\mathrm{D}$ who reported that decreased serum levels of TRAIL correlated to survival among RCC [14]. Furthermore, Liu et al. reported increased survival rates in breast cancer patients with positive expression of TRAIL in their tissues over patients lacking tissue-TRAIL expression [17] On the contrary; Koschny reported the lack of correlation between TRAIL receptors with the progression-free or overall survival among meningioma patients [28].

In conclusion, serum TRAIL levels and TRAIL receptor expression pattern might be useful prognostic markers to follow up disease progression by virtue of their connection to clinical staging and pathologic grading in BC patients, moreover, profiling of TRAIL receptor expression be helpful in determining ideal patients' targets for a TRAIL-mediated gene therapy.

\section{Ethical Approval}

All procedures performed in studies involving human participants were in accordance with the ethical standards of local ethics committee, Medical Research Institute, Alexandria University, and with the 1964 Helsinki declaration and its later amendments or comparable ethical standards. 


\section{Data Availability}

The datasets generated during and/or analyzed during the current study are available from the corresponding author on reasonable request.

\section{Conflicts of Interest}

The authors declare no conflicts of interest regarding the publication of this paper.

\section{References}

[1] Hanahan, D. and Weinberg, R.A. (2011) Hallmarks of Cancer: The Next Generation. Cell, 144, 646-674. https://doi.org/10.1016/j.cell.2011.02.013

[2] Herrnring, C., Reimer, T., Jeschke, U., Makovitzky, J., Kruger, K., et al. (2000) Expression of the Apoptosis-Inducing Ligands FasL and TRAIL in Malignant and Benign Human Breast Tumors. Histochemistry and Cell Biology, 113, 189-194. https://doi.org/10.1007/s004180050438

[3] Rahman, M., Pumphrey, J.G. and Lipkowitz, S. (2009) The TRAIL to Targeted Therapy of Breast Cancer. Advances in Cancer Research, 103, 43-73. https://doi.org/10.1016/S0065-230X(09)03003-6

[4] Sheridan, J.P., Marsters, S.A., Pitti, R.M., Gurney, A., Skubatch, M., Baldwin, D., et al. (1997) Control of TRAIL-Induced Apoptosis by a Family of Signaling and Decoy Receptors. Science, 277, 818-821. https://doi.org/10.1126/science.277.5327.818

[5] MacFarlane, M. (2003) TRAIL-Induced Signalling and Apoptosis. Toxicology Letters, 139, 89-97. https://doi.org/10.1016/S0378-4274(02)00422-8

[6] Lemke, J., von Karstedt, S., Zinngrebe, J. and Walczak, H. (2014) Getting TRAIL Back on Track for Cancer Therapy. Cell Death \& Differentiation, 21, 1350-1364. https://doi.org/10.1038/cdd.2014.81

[7] Cretney, E., Takeda, K., Yagita, H., Glaccum, M., Peschon, J.J., et al. (2002) Increased Susceptibility to Tumor Initiation and Metastasis in TNF-Related Apoptosisinducing Ligand-Deficient Mice. The Journal of Immunology, 168, 1356-1361. https://doi.org/10.4049/jimmunol.168.3.1356

[8] Kriegl, L., Jung, A., Engel, J., Jackstadt, R., Gerbes, A.L., et al. (2010) Expression, Cellular Distribution, and Prognostic Relevance of TRAIL Receptors in Hepatocellular Carcinoma. Clinical Cancer Research, 16, 5529-5538. https://doi.org/10.1158/1078-0432.CCR-09-3403

[9] De Toni, E.N., Thieme, S.E., Herbst, A., Behrens, A., Stieber, P., et al. (2008) OPG Is Regulated by Beta-Catenin and Mediates Resistance to TRAIL-Induced Apoptosis in Colon Cancer. Clinical Cancer Research, 14, 4713-4718. https://doi.org/10.1158/1078-0432.CCR-07-5019

[10] Allred, D.C., Harvey, J.M. and Berardo, M. (1998) Prognostic and Predictive Factors in Breast Cancer by Immunohistochemical Analysis. Modern Pathology, 11, 155-168.

[11] Wolff, A.C., Hammond, M.E. and Schwartz, J.N. (2007) American Society of Clinical Oncology/College of American Pathologists Guideline Recommendations for Human Epidermal Growth Factor Receptor 2 Testing in Breast Cancer. Journal of Clinical Oncology, 25, 118-145. https://doi.org/10.1200/JCO.2006.09.2775

[12] Shlyakhtina, Y., Pavet, V. and Gronemeyer, H. (2017) Dual Role of DR5 in Death and Survival Signaling Leads to TRAIL Resistance in Cancer Cells. Cell Death \& Disease, 8, e3025. https://doi.org/10.1038/cddis.2017.423 
[13] Koschny, R., Ganten, T.M., Sykora, J., Haas, T.L., Sprick, M.R., et al. (2007) TRAIL/Bortezomib Cotreatment Is Potentially Hepatotoxic Butinduces Cancer-Specific Apoptosis within a Therapeutic Window. Journal of Hepatology, 45, 649-658. https://doi.org/10.1002/hep.21555

[14] Toiyama, D., Takaha, N., Shinnoh, M., Ueda, T., Kimura, Y., et al. (2013) Significance of Serum Tumor Necrosis Factor-Related Apoptosis-Inducing Ligand as a Prognostic Biomarker for Renal Cell Carcinoma. Molecular and Clinical Oncology, 1, 69-74. https://doi.org/10.3892/mco.2012.35

[15] Tecchio, C., Huber, V., Scapini, P., et al. (2004) IFNalpha-Stimulated Neutrophils and Monocytes Release a Soluble Form of TNF-Related Apoptosis-Inducing Ligand (TRAIL/Apo-2 Ligand) Displaying Apoptotic Activity on Leukemic Cells. Blood, 103, 3837-3844. https://doi.org/10.1182/blood-2003-08-2806

[16] Tanaka, H., Ito, T., Kyo, T. and Kimura, A. (2007) Treatment with IFNalpha in Vivo Up-Regulates Serum-Soluble TNF-Related Apoptosis Inducing Ligand (sTRAIL) Levels and TRAIL mRNA Expressions in Neutrophils in Chronic Myelogenous Leukemia Patients. European Journal of Haematology, 78, 389-398. https://doi.org/10.1111/j.1600-0609.2007.00834.x

[17] Liu, X.H., Deng, C.X., Hu, P.C., Wang, Y. and Dong, Y.H. (2017) Functional Impact of Galectin-3 and TRAIL Expression in Breast Cancer Cells. European Review for Medical and Pharmacological Sciences, 21, 3626-3633.

[18] Moriwaki, K., Shinzaki, S. and Miyoshi, E. (2011) GDP-Mannose-4,6-Dehydratase (GMDS) Deficiency Renders Colon Cancer Cells Resistant to Tumor Necrosis Factor-Related Apoptosis-Inducing Ligand (TRAIL) Receptor- and CD95-Mediated Apoptosis by Inhibiting Complex II Formation. The Journal of Biological Chemistry, 286, 3123-43133. https://doi.org/10.1074/jbc.M111.262741

[19] Woo, J.K., Kang, J.H., Jang, Y.S., Ro, S., Cho, J.M., Kim, H.M., Lee, S.J. and Oh, S.H. (2015) Evaluation of Preventive and Therapeutic Activity of Novel Non-Steroidal Anti-Inflammatory Drug, CG100649, in Colon Cancer: Increased Expression of TNF-Related Apoptosis-Inducing Ligand Receptors Enhance the Apoptotic Response to Combination Treatment with TRAIL. Oncology Reports, 33, 1947-1955. https://doi.org/10.3892/or.2015.3793

[20] Lemke, J., Noack, A., Adam, D., Tchikov, V., Bertsch, U., et al. (2010) TRAIL Signaling Is Mediated by DR4 in Pancreatic Tumor Cells Despite the Expression of Functional DR5. Journal of Molecular Medicine, 88, 729-740.

https://doi.org/10.1007/s00109-010-0619-0

[21] MacFarlane, M., Kohlhaas, S.L., Sutcliffe, M.J., Dyer, M.J. and Cohen, G.M. (2005) TRAIL Receptor-Selective Mutants Signal to Apoptosis via TRAIL-R1 in Primary Lymphoid Malignancies. Cancer Research, 65, 11265-11270. https://doi.org/10.1158/0008-5472.CAN-05-2801

[22] Stadel, D., Mohr, A., Ref, C., MacFarlane, M., Zhou, S., et al. (2010) TRAIL-Induced Apoptosis Is Preferentially Mediated via TRAIL Receptor 1 in Pancreatic Carcinoma Cells and Profoundly Enhanced by XIAP Inhibitors. Clinical Cancer Research, 16, 5734-5749. https://doi.org/10.1158/1078-0432.CCR-10-0985

[23] Van der Sloot, A.M., Tur, V., Szegezdi, E., Mullally, M.M., Cool, R.H., et al. (2006) Designed Tumor Necrosis Factor-Related Apoptosis-Inducing Ligand Variants Initiating Apoptosis Exclusively via the DR5 Receptor. Proceedings of the National Academy of Sciences of the United States of America, 103, 8634-8639. https://doi.org/10.1073/pnas.0510187103

[24] Yu, R., Albarenque, S.M., Cool, R.H., Quax, W.J., Mohr, A., et al. (2014) DR4 Specific TRAIL Variants Are More Efficacious than Wild-Type TRAIL in Pancreatic 
Cancer. Cancer Biology \& Therapy, 15, 1658-1666. https://doi.org/10.4161/15384047.2014.972183

[25] Zhang, Y. and Zhang, B. (2008) TRAIL Resistance of Breast Cancer Cells Is Associated with Constitutive Endocytosis of Death Receptors 4 and 5. Molecular Cancer Research, 6, 1861-1871. https://doi.org/10.1158/1541-7786.MCR-08-0313

[26] Shirley, S., Morizot, A. and Micheau, O. (2011) Regulating TRAIL Receptor-Induced Cell Death at the Membrane: A Deadly Discussion. Recent Patents on Anti-Cancer Drug Discovery, 6, 311-323. https://doi.org/10.2174/157489211796957757

[27] Yoldas, B., Ozer, C., Ozen, O., et al. (2011). Clinical Significance of TRAIL and TRAIL Receptors in Patients with Head and Neck Cancer. Head Neck, 33, 1278-1284. https://doi.org/10.1002/hed.21598

[28] Koschny, R., Krupp, W., Xu, L.X., Mueller, W.C., Bauer, M., et al. (2015) WHO Grade Related Expression of TRAIL-Receptors and Apoptosis Regulators in Meningioma. Pathology_Research and Practice, 211, 109-116. https://doi.org/10.1016/j.prp.2014.11.002

[29] Clancy, L., Mruk, K., Archer, K., Woelfel, M., Mongkolsapaya, J., et al. (2005) Preligand Assembly Domain-Mediated Ligand-Independent Association between TRAIL Receptor 4 (TR4) and TR2 Regulates TRAIL-Induced-Apoptosis. Proceedings of the National Academy of Sciences of the United States of America, 102, 18099-18104. https://doi.org/10.1073/pnas.0507329102

[30] Riccioni, R., Pasquini, L., Mariani, G., Saulle, E., Rossini, A., et al. (2005) TRAIL Decoy Receptors Mediate Resistance of Acute Myeloid Leukemia Cells to TRAIL. Haematologica, 90, 612-624.

[31] Morizot, A., Merino, D., Lalaoui, N., Jacquemin, G., Granci, V., et al. (2011) Chemotherapy Overcomes TRAIL-R4-Mediated TRAIL Resistance at the DISC Level. Cell Death \& Differentiation, 18, 700-711. https://doi.org/10.1038/cdd.2010.144

[32] Verim, A., Turan, S., Farooqi, A.A., Kahraman, O.T., Tepe-Karaca, C., et al. (2014) Association between Laryngeal Squamous Cell Carcinoma and Polymorphisms in Tumor Necrosis Factor Related Apoptosis Induce Ligand (TRAIL), TRAIL Receptor and sTRAIL Levels. Asian Pacific Journal of Cancer Prevention, 15, 10697-10703. https://doi.org/10.7314/APJCP.2014.15.24.10697 